\title{
Posterior shoulder dislocation with associated reverse Hill-Sachs lesion: treatment options and functional outcome after a 5-year follow up
}

\author{
Markus Guehring ${ }^{1}$, Simon Lambert ${ }^{2}$, Ulrich Stoeckle ${ }^{1}$ and Patrick Ziegler ${ }^{1 *}$ (D)
}

\begin{abstract}
Background: The current study describes several surgical techniques for the treatment of the reverse Hill - Sachs lesion after posterior shoulder dislocation; we also aimed to present long term results followed for a minimum of five years.

Methods: This study is a prospective case series of 17 patients who were treated in our clinic between 2008 and 2011. Patients with a defect size smaller than $25 \%$ of the articular surface were treated conservatively. An endoprosthesis of the glenohumeral joint was implanted in patients with a defect size bigger than $40 \%$. All remaining patients were treated by a variety of operative techniques, depending on the quality of the bone and size of the defect.

Results: Twelve of seventeen patients had a defect size of the humeral articular surface between 25\% and $40 \%$ with a mean age of 39 years. Depending on the defect size these patients were treated with retrograde chondral elevation, antegrade cylindrical graft or a graft of the iliac bone crest with an open approach. All the procedures showed fair results, e.g. the open approach with a graft of the iliac bone crest (2010: Dash 3.89, Constant 90.33, Rowe 86. 67; 2015: Dash 2.22, Constant 92.00, Rowe 93.33).

Conclusion: The open approach is not a disadvantage for the functional outcome. The treatment algorithm should involve the superficial size of the defect as well as the depth of the defect and the time interval between the dislocation and the surgical treatment.
\end{abstract}

Trial registration: 223/2012BO2, 02 August 2010.

Keywords: Posterior shoulder dislocation, Defect size, Osteosynthesis, Outcome

\section{Background}

Posterior shoulder dislocation is a rare injury, comprising $2 \%$ to $5 \%$ of all shoulder dislocations $[1,2]$ and up to $10 \%$ in patients with shoulder instability (mostly polar type II and III according to the Stanmore instability classification). The spectrum of posterior dislocation ranges from acute traumatic dislocation to chronic irreducible dislocations, and in combination with a proximal humeral fracture [3]. An extreme muscle contraction

\footnotetext{
* Correspondence: patrick.ziegler333@googlemail.com

'Department for Traumatology and Reconstructive Surgery, BG Trauma

Center Tübingen, University of Tübingen, Schnarrenbergstr 95, 72076

Tuebingen, Germany

Full list of author information is available at the end of the article
}

(seizures or electric shock), a direct or indirect trauma that occurs with flexion, adduction and internal rotation of the affected arm, is pathognomonic for the posterior shoulder dislocation [4-6].

Cooper first described the typical clinical signs of the posterior shoulder dislocation: dorsal protrusion of the humeral head in accordance with a flattened front shoulder and prominent coracoid, significantly limited or even repealed external rotation, or fixed internal rotation and restricted abduction under 90 degrees [7]. However, in contrast to the anterior shoulder dislocation, there may be very little obvious deformity of the shoulder girdle. Accordingly, the posterior shoulder dislocation is not detected in the primary examination in $60 \%$ to $79 \%$ of the 


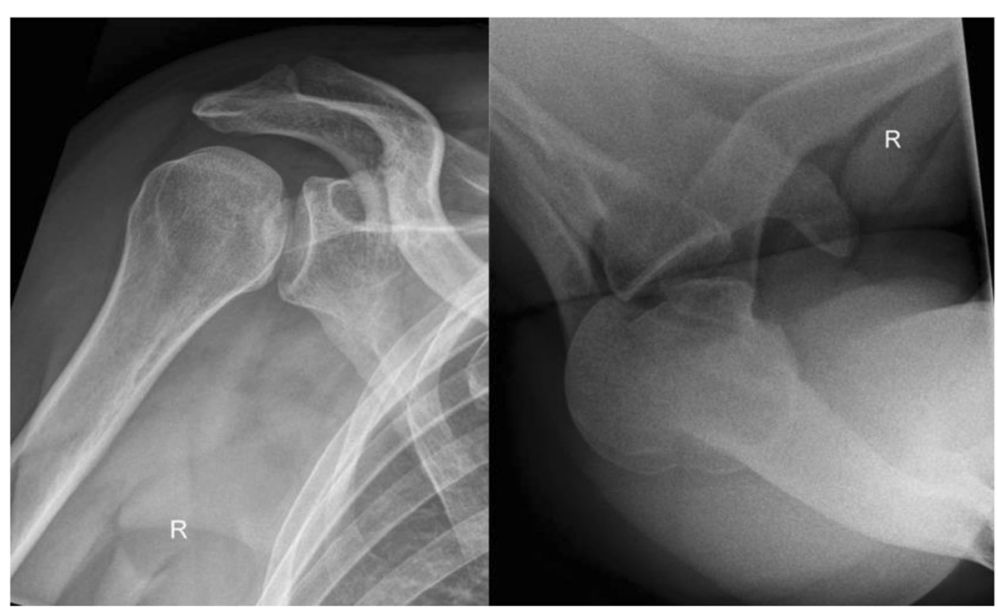

Fig. 1 Axial and ap view of posterior shoulder dislocation

cases $[1,2,8]$. Periods of over 10 years between dislocation and diagnosis are described in the literature [4].

A radiological examination in two views is obligatory (anteroposterior (a-p) and axial; Fig. 1). If pain precludes an axial $x$-ray because of limited abduction, a 'scapular$\mathrm{Y}^{\prime}$ view is recommended, even if there is marked pain. In the a.-p. view the posterior dislocation classically appears as a 'light-bulb' but this is not diagnostic and dislocation is thus sometimes difficult to detect [9]. Moreover, a careful clinical examination (lack of external rotation in a patient with a history of a shoulder injury) is mandatory. Computed tomography $(\mathrm{CT})$ is essential for evaluating the injury and for preoperative planning regarding bone defects in the humeral head (Fig. 2). A magnetic resonance imaging scan (MRI), with contrast, is useful to diagnose lesions of the labrum and rotator cuff $[1,2,4]$, particularly of the incarcerated tendon of the long head of biceps in irreducible dislocations [4]. Compared to anterior shoulder dislocations with defects in the anterior labrum and capsule (that is, soft tissue

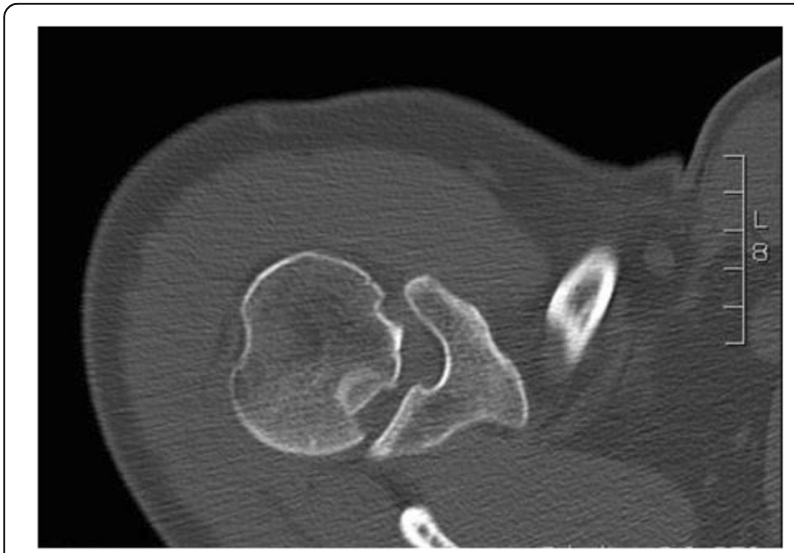

Fig. 2 CT scan after posterior shoulder dislocation lesions), posterior dislocation typically causes bone lesions (the anterior humeral head impression fracture, otherwise known as the "reverse Hill-Sachs lesion", McLaughlin lesion, or "l'encoche de Malgaigne") [5]. Other injuries such as lesions of the posterior labrum, or fractures the posterior glenoid rim are described [10-12]. Treatment depends on the size of the bone defect, the duration of the dislocated condition, and the functional demand of the patient [13].

Conservative treatment is possible with a stable situation after closed reduction and no significant bone defect. Subsequently, the affected shoulder should be immobilized in internal rotation or neutral position over a short period of time $[6,14]$. Depending on the size, the reverse Hill-Sachs lesion is a risk factor for re-dislocation and therefore a surgical treatment is normally recommended [15]. For the treatment of the bone defect in the region of

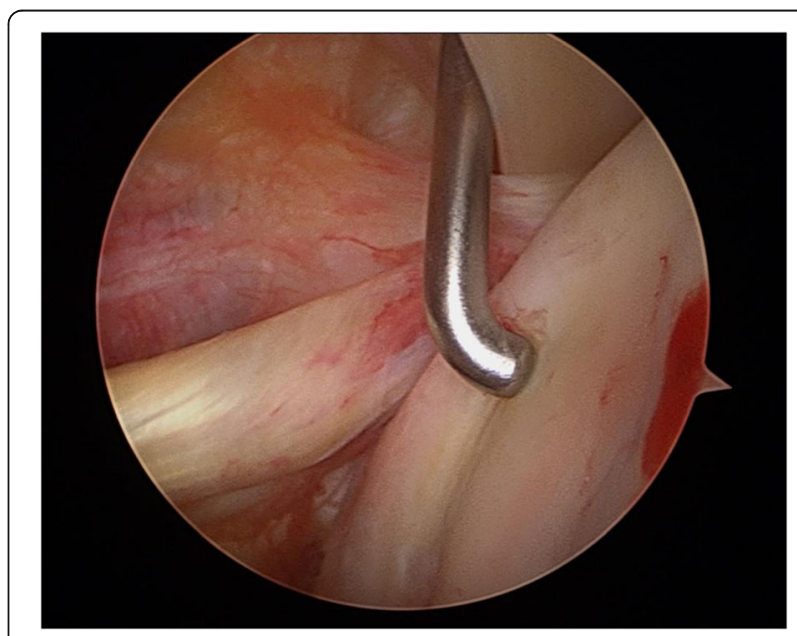

Fig. 3 Diagnostic arthroscopy after posterior shoulder dislocation to detect cartilage defects 


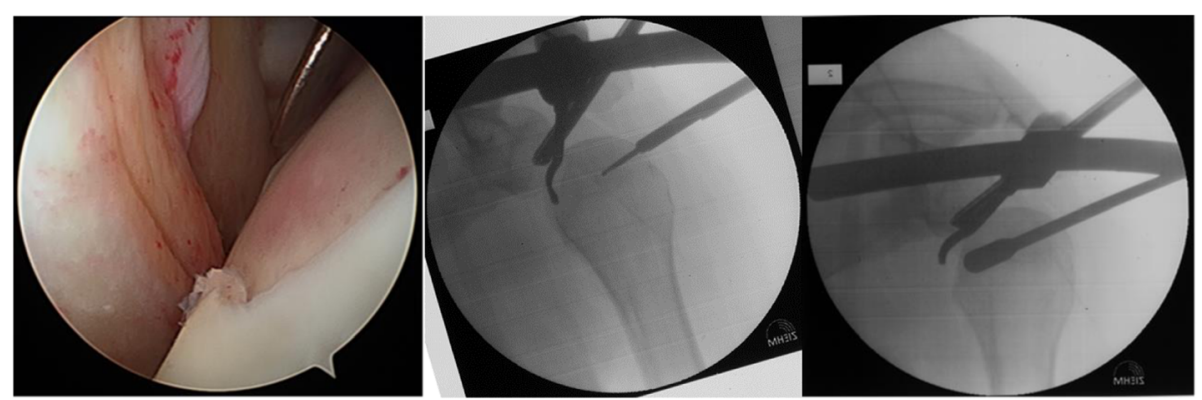

Fig. 4 Arthroscopic retrograde elevation with target device from cruciate ligament surgery

the humeral head, a variety of surgical procedures are described in the literature: filling the defect by tendon transposition of the subscapularis muscle [5], medial transposition of the lesser tuberosity [16] or allograft [17]; rotational osteotomy [18]; and hemi- or total arthroplasty $[19,20]$ are options.

The choice of the surgical technique depends on the size of the bone defect. With a stable shoulder joint and a defect of less than $25 \%$ of the articular surface, conservative treatment normally shows a satisfactory outcome. Reconstruction of the anatomical joint surface is recommended for defects between $25 \%$ and $40 \%$ of the articular surface. Lesions with greater defects than $40 \%$ of the articular surface should be treated with shoulder prosthesis $[16,19]$. The literature of posterior dislocations of the shoulder largely comprises case reports or small series, while studies with a significant number of patients are rare. The aims of the present study are: to evaluate the anatomical reconstruction of the articular surface in a homogeneous patient population; and to evaluate the long-term functional outcomes in the cohort.

\section{Methods}

Between January 2008 and December 2011, 17 patients were treated with a posterior shoulder dislocation. The diagnosis was confirmed by using two orthogonal $\mathrm{x}$-rays of the shoulder joint (anteroposterior (AP) and axial views). Closed reduction of the dislocation was attempted immediately under analgesia and sedation. A CT scan, to evaluate the size of the reverse Hill-Sachs lesion, was undertaken if closed reduction was not possible using the method of Cicak et al [21]. Five patients were excluded from this study. Four patients with defects of less than $25 \%$ of the articular surface in whom the joint was stable after open reduction were treated conservatively. One patient with a defect greater than $40 \%$ of the articular surface had a total shoulder arthroplasty. The remaining twelve patients had a reverse Hill-Sachs compression fracture involving $25-40 \%$ of the articular surface of the humeral head following a traumatic posterior shoulder dislocation.
All patients were male with a mean age of 39 years (range 17-55). The postoperative results were evaluated after a mean of one and five years following intervention using the Constant score [22], the Rowe score [23] and the DASH (disability of the arm, shoulder and hand) score [24]. The subjective perception of pain was evaluated by a VAS (visual analogue scale). No patient had multidirectional instability, prior shoulder surgery, or a neuromuscular disorder.

Diagnostic arthroscopy of the affected shoulder was attempted in all cases. The depth of the bone defect and the cartilage of the humeral articular surface were noted, together with associated injuries of the labrum and the rotator cuff. If no deep lesions of the

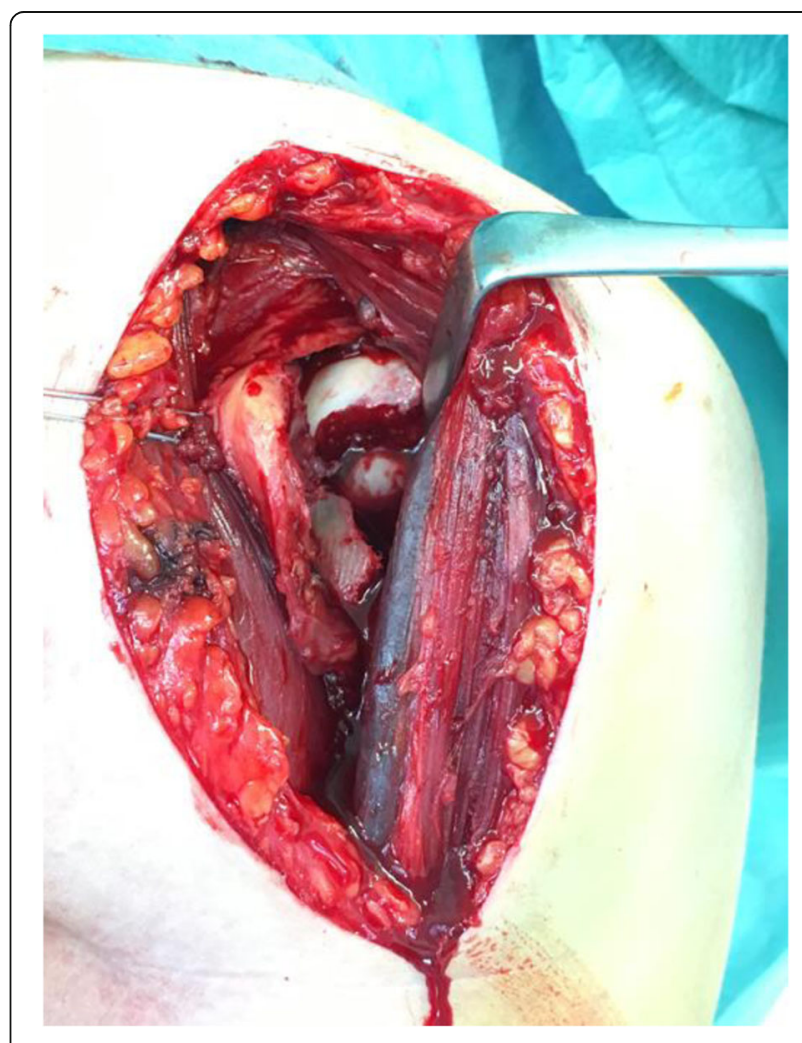

Fig. 5 Open approach for the treatment with an iliac bone crest graft 
cartilage surface were detected during the diagnostic arthroscopy (ICRS classification grade $0-2$, Fig. 3 ) and the time between the shoulder dislocation and the operative treatment was less than 14 days, we elected to restore the joint surface by retrograde elevation with arthroscopic assistance using a target device from the knee ligament surgery (Fig. 4). Larger cartilage lesions (ICRS classification grade $3+4$ ) were treated during open debridement [25] using a deltopectoral approach in all cases (Fig. 5). If the interval between the accident and operative treatment was less than 14 days the joint surface was reconstructed with antegrade cortico-cancellous cylindrical grafts. If the interval was more than 14 days the defect was reconstructed using an autologous iliac crest fixed by small fragment screws (Fig. 6). The therapeutic algorithm is shown in Fig. 7.

\section{Statistical analysis}

Statistical analysis was performed in SPSS (version 22.0, SPSS Inc., Chicago, US). The t-test was used to calculate differences between the one and five year evaluations of pain and function. Differences in outcome between the surgical techniques were calculated using the KruskalWallis variance method.

\section{Results}

The cause of the posterior shoulder dislocation was a high energy trauma in $75 \%$ (8 cases). The average length of in-hospital stay was 7.6 (4-24) days (Table 1).

In five cases with an ICRS score of $0-2$ (42\%), arthroscopically-assisted elevation of the articular surface was performed. Four patients had ICRS grade 3 or higher cartilage lesions, and were treated by antegrade cortico-cancellous cylindrical grafts. Three patients had polytrauma and had definitive treatment of the shoulder more than 14 days after injury using iliac crest corticocancellous graft. There were no postoperative infections, bleeding or nerve injuries, and no complication after harvesting the iliac bone graft. There were no redislocations over the period of review.

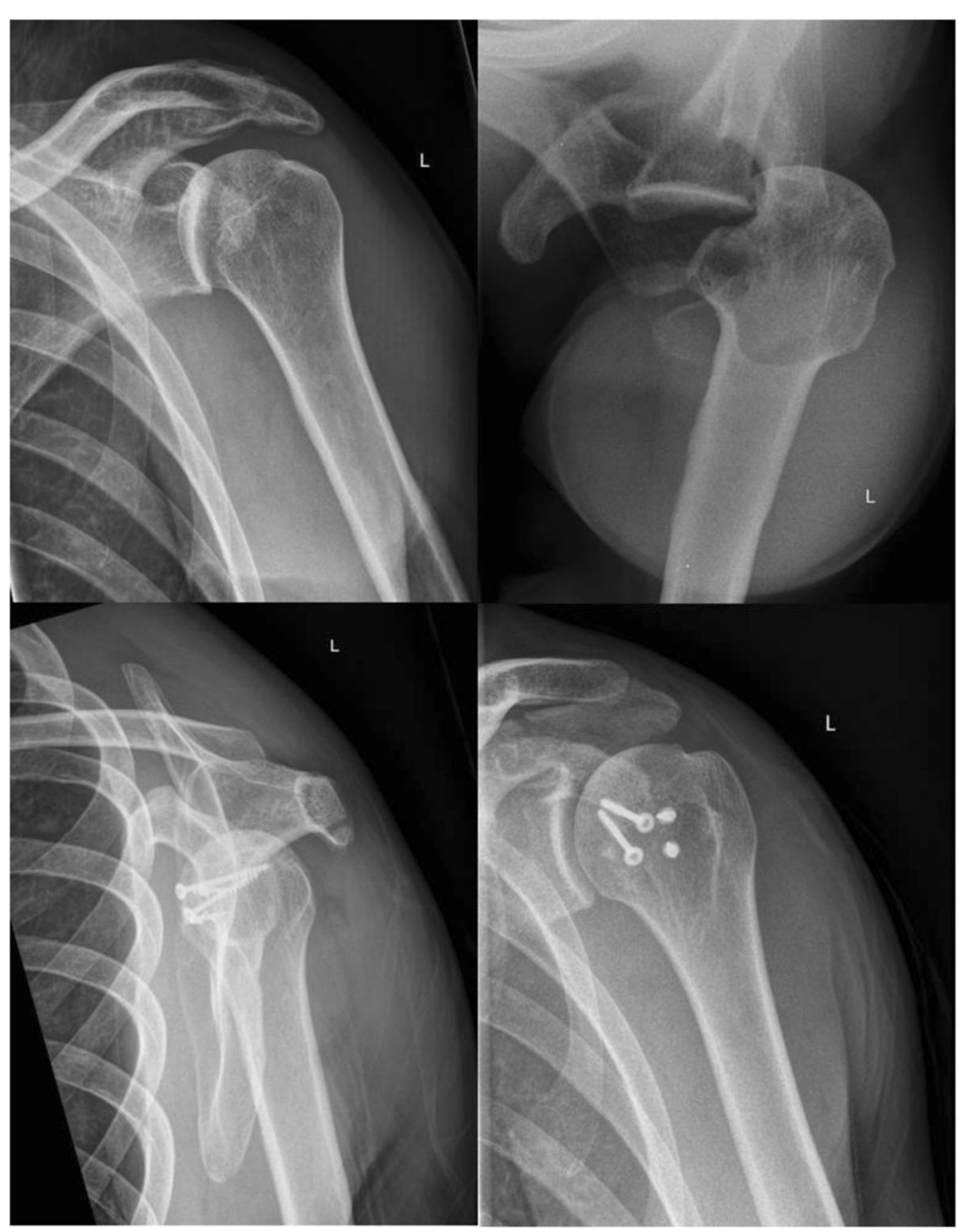

Fig. 6 Before and after reconstruction with an autologous graft of the iliac crest with small fragment screws 


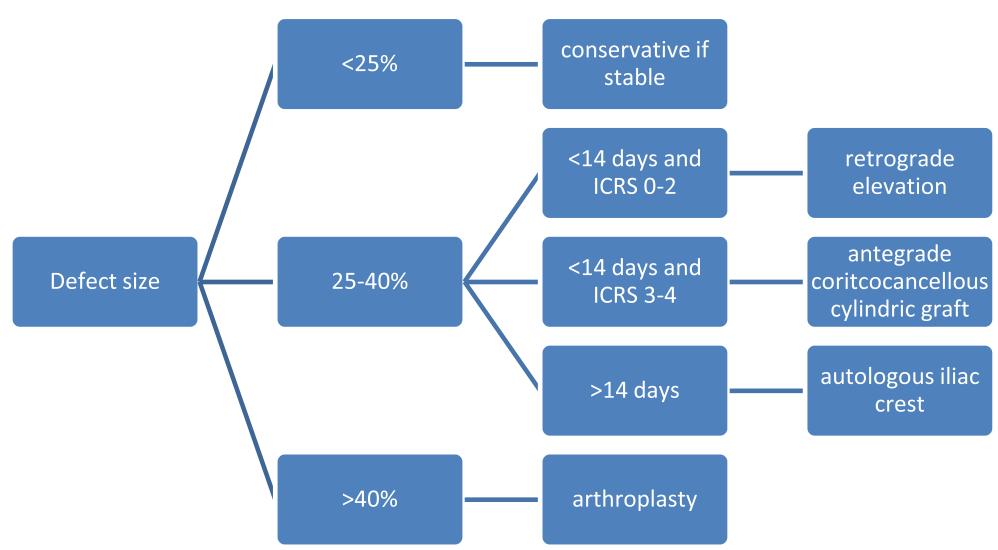

Fig. 7 Treatment algorithm for posterior shoulder dislocations depending on defect size and timer interval between the trauma and surgery

A complete minimum follow up of five years was achieved in all patients. There was an improvement in outcomes at five years compared with the one year results: 5.28 points in the DASH score, 7.58 points in the Constant score, 8 points in the ROWE score and 0.86 points on the VAS on average (Table 2). Patients who were treated with a corticocancellous graft of the iliac crest had the best results after one and five years within the small group of patients (year one: Dash 3.89, Constant 90.33, Rowe 86.67; year five: Dash 2.22, Constant 92.00, Rowe 93.33). This could be demonstrated in all evaluated scores as well as in the VAS (year one, 0.67; year five, 0.5) (Tables 3 and 4).

\section{Discussion}

Optimal treatment of the reverse Hill-Sachs lesion after posterior shoulder dislocation remains controversial. Due to the rare entity of this injury pattern, high numbers of cases in clinical trials are difficult to generate $[17,26]$. The cause of traumatic, non-epileptic posterior dislocation is usually a direct force applied to the adducted and extended arm in internal rotation [3] while

Table 1 Epidemiological data of the patients included in the study

\begin{tabular}{llll}
\hline Criteria & Specification & Total \\
\hline $\begin{array}{l}\text { Total number of } \\
\text { patients }\end{array}$ & Reverse Hill-Sachs lesion[n] & 12 & \\
Age & & $39(17-55)$ \\
Gender & total [y (range)] & 12 & $100 \%$ \\
& male [n] & 0 & $0 \%$ \\
Treatment & female [n] & 5 & $42 \%$ \\
& Arthroscopic reduction and & & \\
& retrograde elevation [n] & & $33 \%$ \\
& Open reduction antegrade & 4 & \\
& cylindric graft [n] & & $25 \%$ \\
Cause of injury & lliac bone crest & 3 & $75 \%$ \\
& High energy trauma [n] & 9 & $17 \%$ \\
& Low energy trauma [n] & 2 & $8 \%$ \\
\hline
\end{tabular}

the mechanism in epilepsy is considered to be a high muscular force generating internal rotation in an adducted arm $[27,28]$. Posterior dislocation of the humeral head may cause a posterior-directed shearing of the labrum or the bony glenoid rim $[29,30]$ but is primarily characterized by the osteochondral impression fracture of the ventromedial articular surface of the humeral head, the so-called reverse Hill-Sachs lesion $[5,31]$. Concomitant neurovascular injuries or lesions of the rotator cuff occur much rarely after posterior dislocation [30, 32]. We observed two lesions of the labrum requiring operative treatment in addition to the reverse Hill-Sachs lesion in this study. These were detected during the diagnostic arthroscopy and accordingly fixed by suture anchors. We did not detect any rotator cuff injuries.

The treatment of posterior instability with a reverse Hill-Sachs lesion considers the arc of stability relative to the arc of rotation of the humeral head with respect to the glenoid surface. The treatment therefore largely depends on the size of the humeral head defect [33]. The surgical strategies are either: the optimization of the surface arc of rotation by restoration of the sphericity of the humeral head (and thereby optimizing the arc of stability), or the restriction of motion of the humeral head relative to the glenoid so that the arc of stability becomes equivalent to the more limited arc of rotation. Various techniques have been described to reconstruct

Table 2 Functional outcome and the VAS after one and five years showed better results in the five year follow up in all evaluated scores

\begin{tabular}{lll}
\hline Score & 2010 & 2015 \\
\hline DASH & $10.49 \pm 2.57$ & $5.21 \pm 1.37$ \\
Constant & $81.92 \pm 3.10$ & $89.50 \pm 2.72$ \\
ROWE & $72.92 \pm 5.56$ & $87.92 \pm 3.61$ \\
VAS & $1.67 \pm 0.36$ & $0.81 \pm 0.19$ \\
\hline
\end{tabular}


Table 3 Functional outcome and the VAS showed the best results for patients treated with an iliac bone crest graft in 2015

\begin{tabular}{lllll}
\hline Score 2015 & $\begin{array}{l}\text { Retrograde } \\
\text { elevation }(n=5)\end{array}$ & $\begin{array}{l}\text { Antegrade cylindric } \\
\text { graft }(n=4)\end{array}$ & $\begin{array}{l}\text { lliac bone crest } \\
(n=3)\end{array}$ & $p$ \\
\hline DASH & $7.33 \pm 2.64$ & $4.79 \pm 2.02$ & $2.22 \pm 1.21$ & .39 \\
Constant & $89.80 \pm 4.66$ & $87.25 \pm 5.59$ & $92.00 \pm 4.61$ & .84 \\
ROWE & $85.00 \pm 7.25$ & $87.50 \pm 6.29$ & $93.33 \pm 3.33$ & .89 \\
VAS & $0.94 \pm 0.30$ & $0.88 \pm 0.43$ & $0.50 \pm 0.29$ & .67 \\
\hline
\end{tabular}

the joint surface defect by osteochondral allograft [34]. Miniaci and Gish performed osteochondral transplantation using fresh-frozen, size-matched allograft in 18 patients with a defect greater than $25 \%$ with an average follow-up of 50 months. The allografts were fixed with Kirschner wires [35]. Outcomes were reasonable with an average Constant score of 78.5 points. Several complications such as osteoarthritis, secondary sintering, subluxation and wire migration were noted. In another series, Diklic et al. recorded an average Constant score of 86.8 points with a follow-up period of 54 months after reconstruction using femoral allograft and fixation with cannulated screws [36]. Gerber and Lambert showed an average Constant score of 82 points in a group of 4 patients after reconstruction of the articular surface by femoral allograft [17]. Krackhart et al. recommended fixing the subscapularis tendon with suture anchors into the defect [37]. This leads to restriction of internal rotation [38].

Only patients with a defect size between 25 and 40\% of the joint surface after posterior shoulder dislocation were included in our study. The patients were reviewed at a mean of one year and five years after surgery. Irrespective of the operative technique used in the present study, we observed a fair outcome with a mean Constant score of 81.92 and 89.50 points respectively. Over time, all of the scores showed an improvement, with low pain scores, related to exercise, at both time points. The best outcome for patients at both time-points was observed after using an autologous iliac crest cortico-cancellous bone graft. This could result from a lower secondary sintering rate of cortico-cancellous bone graft compared to retrograde elevation of the articular surface or antegrade cylindrical osteochondral grafting. These findings have

Table 4 Functional outcome and the VAS showed the best results for patients treated with an iliac bone crest graft in 2010

\begin{tabular}{lllll}
\hline Score 2010 & $\begin{array}{l}\text { Retrograde } \\
\text { elevation }(n=5)\end{array}$ & $\begin{array}{l}\text { Antegrade cylindric } \\
\text { graft }(n=4)\end{array}$ & $\begin{array}{l}\text { lliac bone crest } \\
(n=3)\end{array}$ & p \\
\hline DASH & $12.17 \pm 4.21$ & $13.33 \pm 5.28$ & $3.89 \pm 0.56$ & .18 \\
Constant & $79.00 \pm 3.70$ & $79.25 \pm 7.33$ & $90.33 \pm 2.33$ & .31 \\
ROWE & $76.00 \pm 8.57$ & $58.75 \pm 8.00$ & $86.67 \pm 8.33$ & .11 \\
VAS & $1.80 \pm 0.37$ & $2.25 \pm 0.85$ & $0.67 \pm 0.33$ & .21 \\
\hline
\end{tabular}

to be interpreted carefully due to the small number of cases of this study.

The limiting factor of this study remains the small number of cases. Nevertheless, we believe the treatment algorithm shown in Fig. 7 is very useful, since it includes the extent of cartilage damage and the interval between the injury and surgical treatment, in addition to the size of the humeral defect.

\section{Conclusion}

This study shows the results and techniques of reconstructive treatment options for reverse Hill-Sachs lesion after posterior shoulder dislocation. The best results were demonstrated in the reconstruction of the joint surface by autologous iliac crest grafts. The open approach does not appear to be a disadvantage for the functional outcome despite the invasiveness. In our opinion, the treatment algorithm of the reverse Hill - Sachs lesion should involve the superficial size of the defect, as well as the depth of the defect and the time interval between the dislocation and the surgical treatment.

\section{Abbreviations}

CT: Computed tomography; DASH: Disability of the arm, shoulder and hand; ICRS: International Cartilage Repair Society; MRI: Magnetic resonance imaging; SD: Standard Deviation; VAS: Visual analogue scale

\section{Acknowledgements}

Not applicable

Funding

There is no funding source.

\section{Availability of data and materials}

The datasets used and analyzed during the current study are available from the corresponding author on reasonable request.

\section{Authors' contributions}

MG has initiated the study, has made the data collection and interpretation. PZ has made the statistics, written the manuscript and has analyzed most of the data. SL and US have helped with analyzing the data and supervised the development of the study. All authors read and approved the final manuscript.

\section{Ethics approval and consent to participate}

Informed written consent was obtained from all individual participants included in the study. The study was conducted according to the Helsinki Declaration (Ethical Principles for Medical Research Involving Human Subjects) and was approved by the University of Tuebingen ethics committee.

\section{Consent for publication}

Not Applicable

\section{Competing interests}

The authors declare that they have no competing interests.

\section{Publisher's Note}

Springer Nature remains neutral with regard to jurisdictional claims in published maps and institutional affiliations.

\section{Author details}

1Department for Traumatology and Reconstructive Surgery, BG Trauma Center Tübingen, University of Tübingen, Schnarrenbergstr 95, 72076 
Tuebingen, Germany. ${ }^{2}$ Shoulder and Elbow Service, Royal National Orthopaedic Hospital, Stanmore HA7 4LP, UK.

Received: 2 July 2017 Accepted: 6 November 2017 Published online: 13 November 2017

\section{References}

1. Kowalsky MS, Levine WN. Traumatic posterior glenohumeral dislocation: classification, pathoanatomy, diagnosis, and treatment. Orthop Clin North Am. 2008;39(4):519-33.

2. Hatzis N, Kaar TK, Wirth MA, Rockwood CA Jr. The often overlooked posterior dislocation of the shoulder. Tex Med. 2001;97(11):62-7.

3. Robinson CM, Aderinto J. Posterior shoulder dislocations and fracturedislocations. J Bone Joint Surg Am. 2005;87(3):639-50.

4. Hawkins RJ, Neer CS, 2nd, Pianta RM, Mendoza FX. Locked posterior dislocation of the shoulder. J Bone Joint Surg Am 1987;69(1):9-18.

5. Mc LH. Posterior dislocation of the shoulder. J Bone Joint Surg Am. 1952; 24(3):584-90.

6. Itoi E, Hatakeyama Y, Kido T, Sato T, Minagawa H, Wakabayashi I, Kobayashi M. A new method of immobilization after traumatic anterior dislocation of the shoulder: a preliminary study. J Shoulder Elb Surg. 2003;12(5):413-5.

7. Cooper A. On the dislocations of the os humeri upon the dorsum scapulae, and upon fractures near the shoulder joint. Guy's Hosp Rep. 1839;4:265-84.

8. Rowe CR, Zarins B. Chronic unreduced dislocations of the shoulder. J Bone Joint Surg Am. 1982;64(4):494-505.

9. Pfister $\mathrm{U}$, Rohner $\mathrm{H}$, Weller $\mathrm{S}$. Diagnosis and therapy of traumatic posterior shoulder dislocations. Unfallchirurgie. 1985;11(1):12-6.

10. Irlenbusch L, Pyschik M, Hein W, Brehme K. Possibilities for the operative treatment of traumatic posterior shoulder dislocation. Unfallchirurg. 2008; 111(6):464-8.

11. O'Connor SJ, Jacknow AS. Posterior dislocation of the shoulder. AMA Arch Surg. 1956;72(3):479-91.

12. Wilson JC, MC KF. Traumatic posterior dislocation of the humerus. J Bone Joint Surg Am. 1949;160(72):31A-1.

13. Schliemann B, Muder D, Gessmann J, Schildhauer TA, Seybold D. Locked posterior shoulder dislocation: treatment options and clinical outcomes. Arch Orthop Trauma Surg. 2011;131(8):1127-34.

14. Seybold D, Gekle C, Fehmer T, Pennekamp W, Muhr G, Kalicke T. Immobilization in external rotation after primary shoulder dislocation. Chirurg. 2006;77(9):821-6.

15. Bock $P$, Kluger R, Hintermann B. Anatomical reconstruction for reverse hill-Sachs lesions after posterior locked shoulder dislocation fracture: a case series of six patients. Arch Orthop Trauma Surg. 2007;127(7):543-8.

16. Hawkins RJ, fractures ARLD $\mathrm{p}$ h. Selecting treatment, avoiding pitfalls. Orthop Clin North Am. 1987;18(3):421-31.

17. Gerber C, Lambert SM. Allograft reconstruction of segmental defects of the humeral head for the treatment of chronic locked posterior dislocation of the shoulder. J Bone Joint Surg Am. 1996;78(3):376-82.

18. Surin V, Blader S, Markhede G, Sundholm K. Rotational osteotomy of the humerus for posterior instability of the shoulder. J Bone Joint Surg Am. 1990:72(2):181-6.

19. Checchia SL, Santos PD, Miyazaki AN. Surgical treatment of acute and chronic posterior fracture-dislocation of the shoulder. J Shoulder Elb Surg. 1998;7(1):53-65.

20. Sperling JW, Pring M, Antuna SA, Cofield RH. Shoulder arthroplasty for locked posterior dislocation of the shoulder. J Shoulder Elb Surg. 2004;13(5): 522-7.

21. Cicak N. Posterior dislocation of the shoulder. J Bone Joint Surg Br. 2004; 86(3):324-32.

22. Constant CR, Gerber C, Emery RJ, Sojbjerg JO, Gohlke F, Boileau P. A review of the constant score: modifications and guidelines for its use. J Shoulder Elb Surg. 2008;17(2):355-61.

23. Jensen $\mathrm{KU}$, Bongaerts $\mathrm{G}$, Bruhn $\mathrm{R}$, Schneider $\mathrm{S}$. Not all Rowe scores are the same! Which Rowe score do you use? J Shoulder Elb Surg. 2009;18(4):511-4

24. Germann G, Wind G, Harth A. The DASH(disability of arm-shoulder-hand) questionnaire-a new instrument for evaluating upper extremity treatment outcome. Handchir Mikrochir Plast Chir. 1999:31(3):149-52.

25. Brittberg M, Winalski CS. Evaluation of cartilage injuries and repair. J Bone Joint Surg Am. 2003;85-A(Suppl 2):58-69.

26. Martinez AA, Calvo A, Domingo J, Cuenca J, Herrera A, Malillos M. Allograft reconstruction of segmental defects of the humeral head associated with posterior dislocations of the shoulder. Injury. 2008;39(3):319-22.
27. DeToledo JC, Seizures LMR, decubitus I. Aspiration, and shoulder dislocation: time to change the guidelines? Neurology. 2001;56(3):290-1.

28. DeToledo JC, Lowe MR, Ramsay RE. Restraining patients and shoulder dislocations during seizures. J Shoulder Elb Surg. 1999:8(4):300-2.

29. Ovesen J, dislocation SJOP s. Muscle and capsular lesions in cadaver experiments. Acta Orthop Scand. 1986;57(6):535-6.

30. Roberts A, Wickstrom J. Prognosis of posterior dislocation of the shoulder. Acta Orthop Scand. 1971;42(4):328-37.

31. Edelson G, Kelly I, Vigder F, Reis ND. A three-dimensional classification for fractures of the proximal humerus. J Bone Joint Surg Br. 2004;86(3):413-25.

32. Mestdagh H, Maynou C, Delobelle JM, Urvoy P, Butin E. Traumatic posterior dislocation of the shoulder in adults. Apropos of 25 cases. Ann Chir. 1994; 48(4):355-63.

33. Moroder P, Plachel F, Tauber M, Habermeyer P, Imhoff A, Liem D, Lill H, Resch $\mathrm{H}$, Gerhardt C, Scheibel M. Risk of engagement of bipolar bone defects in posterior shoulder instability. Am J Sports Med. 2017:45(12): 2835-9. 363546517714456

34. Kropf EJ, Tjoumakaris FP, Sekiya JK. Arthroscopic shoulder stabilization: is there ever a need to open? Arthroscopy. 2007;23(7):779-84.

35. Miniaci A, Gish G. Management of Anterior Glenohumeral Instability Associated with Large Hill-Sachs Defects. Tech Shoulder Elbow Surg. 2004:5:170-5.

36. Diklic ID, Ganic ZD, Blagojevic ZD, Nho SJ, Romeo AA. Treatment of locked chronic posterior dislocation of the shoulder by reconstruction of the defect in the humeral head with an allograft. J Bone Joint Surg Br. 2010;92(1):71-6.

37. Krackhardt T, Schewe B, Albrecht D, Weise K. Arthroscopic fixation of the subscapularis tendon in the reverse Hill-Sachs lesion for traumatic unidirectional posterior dislocation of the shoulder. Arthroscopy. 2006;22(2):227. e1- e6

38. Verma NN, Sellards RA, Romeo AA. Arthroscopic reduction and repair of a locked posterior shoulder dislocation. Arthroscopy. 2006;22(11):1252. e1-5

\section{Submit your next manuscript to BioMed Central and we will help you at every step:}

- We accept pre-submission inquiries

- Our selector tool helps you to find the most relevant journal

- We provide round the clock customer support

- Convenient online submission

- Thorough peer review

- Inclusion in PubMed and all major indexing services

- Maximum visibility for your research

Submit your manuscript at www.biomedcentral.com/submit
) Biomed Central 